\title{
Chemically treated plasma $A \beta$ is a potential blood-based biomarker for screening cerebral amyloid deposition
}

\author{
Jong-Chan Park', Sun-Ho Han ${ }^{1,2}$, Hyun Jin Cho ${ }^{1}$, Min Soo Byun ${ }^{3}$, Dahyun Yi ${ }^{3}$, Young Min Choe ${ }^{4}$, Seokjo Kang ${ }^{1}$,
} Eun Sun Jung ${ }^{1}$, Su Jin Won', Eun Hye Kim', Yu Kyeong Kim', Dong Young Lee ${ }^{6,7^{*}}$ and Inhee Mook-Jung ${ }^{1,2^{*}}$

\begin{abstract}
Background: Plasma $\beta$-amyloid (AB) is a potential candidate for an Alzheimer's disease (AD) biomarker because blood is an easily accessible bio-fluid, which can be collected routinely, and A $\beta$ is one of the major hallmarks of AD pathogenesis in the brain. However, the association between plasma A $\beta$ levels and AD diagnosis is still unclear due to the instability and inaccurate measurements of plasma $A \beta$ levels in the blood of patients with $A D$. If a consistent value of plasma $A \beta$ from the blood can be obtained, this might help determine whether plasma $A \beta$ is a potential biomarker for AD diagnosis.

Methods: We predicted the brain amyloid deposit by measuring the plasma A $\beta$ levels. This cross-sectional study included 353 participants (215 cognitively normal, 79 with mild cognitive impairment, and 59 with AD dementia) who underwent Pittsburgh-compound B positron emission tomography (PiB-PET) scans. We treated a mixture of protease inhibitors and phosphatase inhibitors (MPP) and detected plasma $A \beta 42$ and A $\beta 40$ (MPP-A 342 and MPP-A $\beta 40$ ) in a stable manner using XMAP technology.

Results: MPP-A $A 40$ and MPP-A $342 / 40$ (MPP-ABs) were significantly different between subjects with positive amyloid deposition $(\mathrm{PiB}+)$ and those with negative amyloid deposition (PiB-) $(P<0.0001)$. Furthermore, MPP-A $40(P<0.0001$, $r=0.23)$ and MPP-A $42 / 40$ ratio $(P<0.0001, r=-0.23)$ showed significant correlation with global PiB deposition (standardized uptake value ratio). In addition, our integrated multivariable (MPP-A $442 / 40$, gender, age, and apolipoprotein E genotypes) logistic regression model proposes a new standard for the prediction of cerebral amyloid deposition.
\end{abstract}

Conclusions: MPP-A $\beta$ might be one of the potential blood biomarkers for the prediction of PiB-PET positivity in the brain.

Keywords: Alzheimer's disease, $\beta$-amyloid, Plasma A $\beta$, Blood-based biomarker, MPP, Pittsburgh-compound B positron emission tomography

\section{Background}

Alzheimer's disease (AD) is the most common cause of dementia usually observed in populations over the age of 65 years and is characterized by $\beta$-amyloid $(A \beta)$ plaques and neurofibrillary tangles in the brain $[1,2]$. The insoluble aggregates of $A \beta$ peptides are associated with cognitive impairment, synapse loss, and neuronal

\footnotetext{
* Correspondence: selfpsy@snu.ac.kr; inhee@snu.ac.kr

${ }^{6}$ Department of Neuropsychiatry, Seoul National University Hospital, 101 Daehak-ro, Jongno-gu, Seoul 110-744, South Korea

${ }^{1}$ Department of Biochemistry and Biomedical Sciences, Seoul National University, College of Medicine, 103 Daehak-ro, Jongno-gu, Seoul 110-799, South Korea

Full list of author information is available at the end of the article
}

cell death, and this may precede the onset of dementia $[3,4]$. In addition, there is no currently available cure for $\mathrm{AD}$, and current drugs only alleviate the symptoms of dementia but do not cure the underlying disease [5]. Abnormal aggregation of $A \beta$ is the earliest pathological event in $\mathrm{AD}$, and existing drugs only slow down $\mathrm{AD}$ progression. Hence, the diagnosis of $\mathrm{AD}$ at the early stages of the disease is the most promising method for effective follow-up measures, although it is very challenging. Furthermore, although $\mathrm{AD}$ has no known cure, early detection of the disease is promising because the devastating disease can be prevented through wellknown methods for reducing risk factors such as doing 
some exercises, healthy diet, controlling blood pressure, having strong social support, taking folic acid supplements, and not smoking [6-11].

Efforts to identify the available and effective biomarkers for $\mathrm{AD}$ have been made in many countries. In the neuroimaging field, specific regional brain atrophy can be observed by magnetic resonance imaging (MRI), and $\mathrm{A} \beta$ deposition in the brain can be detected by positron emission tomography (PET) using specific radioactive ligands including Pittsburgh compound $\mathrm{B}$ (PiB) [12]. However, these are costly procedures for $A D$ diagnosis [13]. Additionally, although molecular biomarkers such as tau and $A \beta$ can be measured in the cerebrospinal fluid (CSF) [14], the collection of CSF is a highly invasive procedure [15].

On the other hand, the blood is an easily accessible bio-fluid which can be routinely collected and analyzed to detect or track the disease [15]. Hence, if we utilize blood proteins as a biomarker for $\mathrm{AD}$, this might help recognize the disease earlier because of the simple method and high frequency of blood collection. Several studies reported the efflux/influx of $A \beta$ across the blood-brain barrier and identified various $A \beta$ transporters; hence, many researchers believe that plasma $A \beta$ might reflect brain amyloid deposition [16]. However, the association between plasma $A \beta$ levels and $A D$ diagnosis is still unclear. Several cross-sectional studies showed that low plasma $A \beta 42$ levels or $A \beta 42 / 40$ ratios are associated with $\mathrm{AD}[17,18]$. Some prospective studies have also suggested that a decrease in plasma A $\beta 42 / 40$ ratio is related to cognitive impairment $[19,20]$. However, these results are in contrast with other reports, which indicate an increase in $A \beta 42$ with cognitive decline [21], no association between plasma $\mathrm{A} \beta$ levels and $\mathrm{AD}$ [22], and a relation between low plasma $\mathrm{A} \beta 40$ and $\mathrm{AD}$ [23]. Thus, evidence for the effectiveness of measurement of plasma $A \beta 42, A \beta 40$, and the $A \beta 42 / 40$ ratios in the diagnosis of $\mathrm{AD}$ is lacking. Such controversy on the relationship between plasma $A \beta$ levels and $A D$ may result from the inaccuracy in both plasma $A \beta$ measurement and $A D$ clinical diagnosis. In addition, plasma $A \beta$ levels show unpredictable fluctuations in their values because of numerous factors. Human serum albumin (HSA) and transthyretin (TTR) interrupt the detection of $A \beta$ [24-27] because both of them bind to $A \beta$, and their interaction status varies depending on blood dynamics [28, 29]. Furthermore, protease inhibitors and phosphatase inhibitors in the blood might play a role in decreasing $A \beta$ degradation because the $A \beta$ sequence contains many possible proteases and phosphorylation sites [30, 31]. After blood collection, both protease inhibitors and phosphatase inhibitors are randomly activated, which affects $A \beta$ degradation and the interaction between $A \beta$ and other proteins in the blood [31, 32], resulting in the fluctuation of the measurable $A \beta$ concentration in the blood.
Moreover, about $12 \%$ of patients with clinically diagnosed AD dementia (ADD) do not exhibit AD pathology, and $23 \%$ of cognitively normal $(\mathrm{CN})$ individuals show AD pathology [3, 33]. Hence, the blood samples from previous studies that did not have PiB-PET data for the participants were not homogeneous samples in the view of brain amyloid pathology, which might have yielded the conflicting results for plasma $A \beta$ level.

In this study, we aimed to investigate the potential of plasma $A \beta$ level as a diagnostic or screening marker for $\mathrm{AD}$. To resolve the instability or inaccuracy in assessment, we applied two distinct approaches. First, all participants underwent PiB-PET to quantify the cerebral $\mathrm{A} \beta$ deposition. This approach allowed us to test the effectiveness of plasma $A \beta$ as a biomarker using pathological AD diagnosis, instead of clinical AD diagnosis, as the gold standard. Second, we developed a novel mixture (MPP, a mixture of protease inhibitors and phosphatase inhibitors) and treated the plasma with MPP to detect plasma $A \beta$ levels in a stable and accurate manner using xMAP technology. Under this new but simple method, we determined that MPP-A $\beta$ might be a reliable blood biomarker for screening cerebral amyloid deposition.

\section{Methods}

This study was part of the Korean Brain Aging Study for Early Diagnosis and Prediction of Alzheimer's Disease (KBASE), an ongoing prospective cohort study aimed at searching for new biomarkers for $\mathrm{AD}$ and elucidating various life experiences contributing to AD-related brain changes. This work was approved by the Institutional Review Board (IRB) of the Seoul National University Hospital, South Korea, and the subjects or their legal representatives provided their written informed consent. Additional file 1 shows the experimental flow chart for this study.

\section{Participants}

Overall 353 middle-aged or old-aged subjects with age $\geq 55$ years, including $215 \mathrm{CN}$ individuals, 79 individuals with mild cognitive impairment (MCI), and 59 individuals with ADD, participated in the study. All participants underwent comprehensive clinical and neuropsychological assessments, neuroimaging examinations including structural MRI and PiB-PET, and comprehensive laboratory blood tests. $\mathrm{CN}$ participants had a Clinical Dementia Rating (CDR) score of 0 [34] and were without diagnoses of MCI or dementia. Individuals with $\mathrm{MCI}$ met the following criteria: (a) memory complaint corroborated by self, an informant, or a clinician; (b) objective memory impairment for age, education, and gender; (c) largely intact functional activities; and (d) not demented. All individuals with $\mathrm{MCI}$ had a global CDR score of 0.5. In terms of criterion (b), all participants with MCI had a performance score at least 1.5 
standard deviation (SD) below the respective age-specific, education-specific, and gender-specific mean for at least one of the four episodic memory tests included in the Consortium to Establish a Registry for Alzheimer's Disease (CERAD) neuropsychological battery (namely, Word List Memory, Word List Recall, Word List Recognition, and Constructional Recall test) [35]. Patients with ADD met both the criteria for dementia (in accordance with the Diagnostic and Statistical Manual, fourth edition (DSMIV)) [36] and the criteria for probable AD set in accordance with the National Institute of Aging and Alzheimer's Association (NIA-AA) guidelines [37]. The exclusion criteria for all participants were: any present serious medical, psychiatric, and neurological disorders that could affect mental function; the presence of severe communication problems that would make a clinical examination or brain scan difficult; contraindications for MRI scan (e.g., pacemaker, claustrophobia); absence of a reliable informant; and illiteracy.

\section{Clinical and neuropsychological assessment}

Participants were administered standardized clinical assessments based on the KBASE clinical assessment protocol, which incorporated the Korean version of the Consortium to Establish a Registry for Alzheimer's Disease Assessment Packet (CERAD-K) [38], by trained psychiatrists. They were also administered the KBASE neuropsychological assessment protocol incorporating the CERAD neuropsychological battery [35], which included the Mini-Mental State Examination (MMSE), by trained neuropsychologists. In this study we used the MMSE $z$ score, with consideration for age, gender, and education levels, because the basic demographic information of subjects such as gender, age, and education is known to have an effect on the change in MMSE scores [39].

\section{Blood sampling}

Blood samples were obtained via venipuncture in the morning (around 9:00 am) after an overnight fast and collected several hours before the injection of PET tracer in K2 ethylenediaminetetraacetic acid (EDTA) tubes (BD Vacutainer Systems, Plymouth, UK). The samples were stabilized and centrifuged at $700 \times g$ for $5 \mathrm{~min}$ at room temperature (RT) to obtain the plasma supernatants in 15-ml centrifuge tubes (SPL Life Sciences Co., Gyeonggi-do, Korea). To obtain the samples with high purity, the plasma supernatants were further centrifuged under the same conditions, and the collected pure plasma supernatants were aliquoted and stored immediately at $-80{ }^{\circ} \mathrm{C}$.

\section{PiB-PET}

Participants underwent simultaneous three-dimensional PiB-PET imaging and T1-weighted MR using a Biograph
mMR scanner (Siemens, Washington, DC, USA) with the manufacturer's approved guidelines. A 30-min emission scan was acquired after $40 \mathrm{~min}$ of intravenous administration of $555 \mathrm{MBq}$ of ${ }^{11} \mathrm{C}-\mathrm{PiB}$ (range, $450-610 \mathrm{MBq}$ ). The PiB-PET data collected in the list mode were processed for routine corrections such as uniformity, ultrashort echo time (UTE)-based attenuation, and decay corrections and were reconstructed into a $256 \times 256$ image matrix using iterative methods (six iterations with 21 subsets). T1-weighted scans (repetition time $=1670 \mathrm{~ms}$; echo time $=1.89 \mathrm{~ms}$; field of view $=250 \mathrm{~mm} ; 256 \times 256$ matrix with $1.0 \mathrm{~mm}$ slice thickness) were acquired in the sagittal orientation. The following image preprocessing steps were performed using Statistical Parametric Mapping 8 (SPM8) implemented in MATLAB 2014a (MathWorks, Natick, MA, USA). Static PiB-PET images were coregistered to the individual T1 structural images and transformation parameters for spatial normalization of the individual T1 images to a standard Montreal Neurological Institute (MNI) template were calculated. Utilizing Individual Brain Atlases using Statistical Parametric Mapping Software (IBASPM) software, the inverse transformation parameters were used to transform the coordinates from the automatic anatomic labeling (AAL) 116 atlas [40] into an individual space for each subject (resampling voxel size $=1 \times 0.98 \times$ $0.98 \mathrm{~mm}^{3}$ ). The nongray matter portions of the atlas were individually masked using the cerebral gray matter segment image from each subject.

The mean regional ${ }^{11} \mathrm{C}$-PiB uptake values from the cerebral regions were extracted using the individual AAL116 atlas from the T1-coregistered PiB-PET images. The cerebellar gray matter was used as the reference region due to its relatively low $A \beta$ deposition for the quantitative normalization of cerebral ${ }^{11} \mathrm{C}$-PiB uptake values. To measure the ${ }^{11} \mathrm{C}$ - $\mathrm{PiB}$ uptake in the cerebellar gray matter regions, a probabilistic cerebellar atlas (Institute of Cognitive Neuroscience, UCL; Cognitive Neuroscience Laboratory, Royal Holloway) was transformed into an individual space in the same manner as already described. Of the 28 anatomical structural regions in the cerebellar atlas, all of the cerebellar lobular regions except for the vermis were included to extract the mean cerebellar uptake values. The AAL algorithm and a region-combining method [20] were applied to determine the regions of interest (ROIs) to characterize the ${ }^{11} \mathrm{C}-\mathrm{PiB}$ retention level in the frontal, lateral parietal, posterior cingulate-precuneus (PC-PRC), and lateral temporal regions, where prominent ${ }^{11} \mathrm{C}-\mathrm{PiB}$ retention has been reported [13].

The standardized uptake value ratio (SUVR) values for each ROI were calculated by dividing the mean value for all voxels within each ROI by the mean cerebellar uptake value in the same image. Each participant was classified as $\mathrm{PiB}$-positive $(\mathrm{PiB}+)$ if the SUVR value was $>1.4$ in at least one of the four ROIs (i.e., frontal, lateral temporal, 
lateral parietal, and $\mathrm{PC}-\mathrm{PRC}$ ) or $\mathrm{PiB}$-negative (PiB-) if the SUVR values of all four ROIs were $\leq 1.4$ [17]. A global cortical ROI consisting of the four ROIs was also defined, and a global PiB deposition value (SUVR) was generated by dividing the mean value for all voxels of the global cortical ROI by the mean cerebellar uptake value of the same image.

\section{Reagents}

The mixture of protease inhibitors and phosphatase inhibitors (MPP) was composed of protease inhibitor cocktail (PI), phenylmethanesulfonyl fluoride (PMSF, a serine protease inhibitor; Sigma-Aldrich, CA, USA), and phosphatase inhibitor cocktail I and II (PPI I and II; A. G. Scientific, Inc., CA, USA). They were mixed in the same proportion. $A \beta$ peptide was purchased from Bachem Americas, Inc. (Torrance, CA, USA) and prepared as described previously [41]. HSA (Sigma-Aldrich) was used for mimicking the plasma sample condition because it is the most abundant protein in the human plasma [25, 42, 43].

INNO-BIA plasma $A \beta$ forms assay using XMAP technology To simultaneously determine the concentrations of plasma $A \beta 42$ and $A \beta 40$, the INNO-BIA plasma $A \beta$ forms kit (Innogenetics, Gent, Belgium) was used in accordance with the manufacturer's guidelines. In brief, the samples were diluted 3-fold in the MPP-treated plasma diluent buffer (final concentration, 4\% MPP solution in plasma diluent buffer) or MPP nontreated plasma diluent buffer and incubated for $30 \mathrm{~min}$ at RT. After washing the filter plate, the diluted bead mix was transferred to the wells of the plate. The plate was dried gently, washed, and $25 \mu \mathrm{l}$ of conjugate 1 working solution $\mathrm{A}$ and $75 \mu \mathrm{l}$ of standards, blanks, controls, and diluted plasma samples were added. The plate was incubated overnight at $4{ }^{\circ} \mathrm{C}$, and the next day each well was washed with $100 \mu \mathrm{l}$ of the detection solution added to the mixture. After $1 \mathrm{~h}$, the plates were washed again, and the reading solution was added to each well. The levels of plasma $A \beta$ were measured using xMAP technology (Bioplex 200 systems; Bio-Rad, Hercules, CA, USA).

\section{Proof-of-concept experiments Gel electrophoresis}

We prepared the synthetic $A \beta 42$ (diluted in $1 \times$ phosphate buffered saline (PBS), $2 \mu \mathrm{M})$ to visualize the change in $A \beta$ form against MPP treatment. $A \beta 42$ solution was equally divided $(20 \mu \mathrm{l})$ among eight $1.5 \mathrm{ml}$ tubes. For repetitive measurement assay without plasma (pure synthetic A 442 ), $20 \mu \mathrm{l}$ of $8 \%$ dimethyl sulfoxide (DMSO) in $1 \times$ PBS $(-\mathrm{MPP})(n=4$; Fig. $2 \mathrm{a}$, lanes $1-4)$ or $8 \%$ MPP solution in $1 \times$ PBS $(+\mathrm{MPP})(n=4$; Fig. $2 \mathrm{a}$, lanes
5-8) was added to the $A \beta 42$ solution (final concentration: $1 \mu \mathrm{M}$ of $\mathrm{A} \beta 42$ ). For repetitive measurement assay with the original plasma sample, $20 \mu \mathrm{l}$ of $8 \%$ DMSO and $25 \%$ plasma in $1 \times$ PBS $(-\mathrm{MPP})(n=4$; Fig. $2 \mathrm{~b}$, lanes $1-4)$ or $8 \%$ MPP solution and $25 \%$ plasma in $1 \times$ PBS $(+\mathrm{MPP})$ ( $n=4$; Fig. 2b, lanes 5-8) was added to the A $\beta 42$ solution (final concentration: $1 \mu \mathrm{M}$ of $\mathrm{A} \beta 42$ ). The samples were incubated for $30 \mathrm{~min}$ at RT and then mixed with $4 \times$ sample buffer (without boiling) and loaded equally on 4-12\% NuPAGE bis-tris gel (Thermo Fisher Scientific, Waltham, MA, USA) for gel electrophoresis. Next, the gel was transferred to a polyvinylidene difluoride (PVDF) membrane for $60 \mathrm{~min}$ at $70 \mathrm{~V}$, and the membrane was blocked with $5 \%$ skim milk in $1 \times$ Tris buffered saline with Tween 20 (TBST) for $1 \mathrm{~h}$. After blocking, the membrane was incubated with anti-6E10 A $\beta$ antibody (primary antibodies overnight at $4{ }^{\circ} \mathrm{C}$ ) and the following day with secondary antibodies for $1 \mathrm{~h}$ at RT. The protein bands on the PVDF membrane were visualized using a bio-imaging analyzer (LAS-3000; Fujifilm Corporation, Tokyo, Japan) with a chemiluminescence detection solution (Ab Frontier Co., Seoul, Korea). The images were imported from a Multi-Gauge program (Fujifilm Corporation), and the band intensities (ratio, \%) were measured (monomeric $\mathrm{A} \beta, \sim 4 \mathrm{kDa}$; oligomeric A $\beta, 8-14 \mathrm{kDa}$ ) [44].

\section{xMAP technology}

We repetitively measured the synthetic $A \beta$ and plasma $A \beta$ levels using xMAP technology. For synthetic A $\beta$ levels, $4 \%$ MPP solution (or absent), 0.5\% HSA (or absent), and A $\beta 42$ $(200 \mathrm{pg} / \mathrm{ml}$ ) (aliquots from the same pool, in separate 1.5-ml tubes; -MPP or + MPP, each $n=6$ ) in Bioplex sample diluent buffer were incubated for $30 \mathrm{~min}$ at RT, followed by A 422 measurement using xMAP technology. For plasma $A \beta$ levels, samples (aliquots from the same pooled plasma, in separate $1.5-\mathrm{ml}$ tubes, $n=5$ ) were diluted 3-fold in MPP-treated plasma diluent buffer (final concentration, 4\% MPP solution in plasma diluent buffer) or MPP nontreated plasma diluent buffer, incubated for $30 \mathrm{~min}$ at RT, and then measured using xMAP technology (-MPP or + MPP, each $n=5)$.

\section{Time-dependent alterations in plasma $A \beta 42$ and $A \beta 40$ levels}

Plasma $A \beta 42$ and $A \beta 40$ levels were quantified in a timedependent manner using xMAP technology. We used individual human plasma samples $(n=4)$ and also diluted them 3-fold in MPP-treated plasma diluent buffer (final concentration, 4\% MPP solution in plasma diluent buffer) or MPP nontreated plasma diluent buffer, and incubated at RT followed by measurement at each time point $(0,6,12,24 \mathrm{~h})$ and quantification (-MPP or + MPP, each $n=4)$. 
Effects of MPP on discrimination between subject groups

Plasma samples (20 CN-, $12 \mathrm{MCI}+, 23 \mathrm{ADD}+$, total of 55 subjects; - and + , PiB-PET positivity) were diluted 3-fold in MPP-treated plasma diluent buffer (final concentration, 4\% MPP solution in plasma diluent buffer) or MPP nontreated plasma diluent buffer and incubated for $30 \mathrm{~min}$ at RT followed by measurement using xMAP technology. We compared the intergroup differences in MPP-treated plasma A $\beta$ (MPP-A $\beta$ ) with those of nonMPP-treated plasma A $\beta$ (nMPP-A $\beta$ ).

\section{Statistics}

Statistical analysis was performed using GraphPad Prism 5 (GraphPad Software, San Diego, CA, USA) and Medcalc (Medcalc Software, Ostend, Belgium). All data are presented as mean \pm standard error of mean (SEM). An unpaired $t$ test was used to assess the quantitative differences between two groups. For the tests of differences between three groups or more, multifactorial analyses of variance (ANOVA) followed by Tukey's multiple comparisons tests were performed. We used a bivariate correlation analysis to test the association between variables. Furthermore, we conducted logistic regression analysis followed by receiver operating characteristic (ROC) curve analysis on these values using Medcalc software. Cutoff criteria (optimal cutoff point) were determined by the Youden index [45] with an appropriate balance between sensitivity and specificity. Pearson's chi-square test $\left(X^{2}\right)$ was carried out to evaluate the intergroup differences of two-category variables (gender, apolipoprotein E $\varepsilon 4$ carrier status) using Medcalc software. To compare the variance between -MPP and + MPP in the repetitive measurement assay, an $F$ test was performed (GraphPad Prism 5). Squared deviation $\left((\text { value - mean value })^{2}\right)$ indicates how far each point is from the mean value. Because the $y$ axis of the graphs indicates the squared deviation in Fig. $2 \mathrm{a}-\mathrm{d}$, the highest points of each bar graph equates to 'Variance':

$$
\text { Variance }=\sum\left\{(X-m)^{2} / N\right\},
$$

where $X$ is an individual data point, $m$ is the mean of data points, and $N$ is the total number of data points. Statistically significant results were shown as the appropriate $P$ value.

\section{Results}

\section{Demographic data of subjects}

A total of 353 subjects were included in this study. Subjects were classified according to their pathological (brain $A \beta$ deposition) and/or clinical diagnosis (Fig. 1, Table 1, and Additional file 2). Two hundred and fiftythree subjects with negative amyloid deposition ( $\mathrm{PiB}-$ ) and 100 subjects with positive amyloid deposition $(\mathrm{PiB}+)$

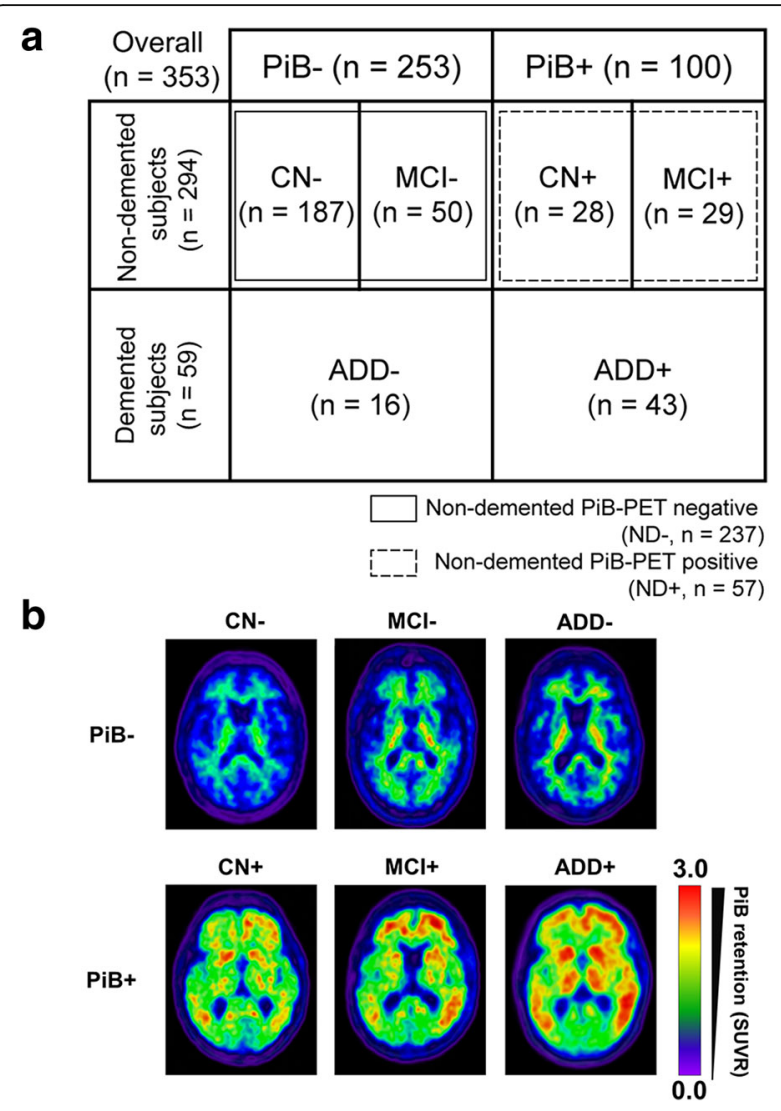

Fig. 1 Categorized subject groups. a Classification of subjects $(n=353)$ for the study. $\mathbf{b}$ Representative PiB-PET images of the study cohort $(n=353)$. Participants were classified as PiB-positive (PiB+) if the $\mathrm{PiB}$ retention (SUVR) value was $>1.4$ in at least one of the four ROls (i.e., frontal, lateral temporal, lateral parietal, and PC-PRC) or PiB-negative (PiB-) if the SUVR values of all four ROls were $\leq 1.4$. - or + PiB-PET positivity, $C N$ cognitively normal, $M C l$ mild cognitive impairment, $A D D$ Alzheimer's disease dementia, ND nondemented, PiB-PET Pittsburgh-compound B positron emission tomography, SUVR standard uptake value ratio (Color figure online)

were included; out of which 187 were $\mathrm{PiB}-\mathrm{CN}(\mathrm{CN}-)$, 50 were $\mathrm{PiB}-\mathrm{MCI}$ (MCI-), 16 were $\mathrm{PiB}-\mathrm{ADD}$ (ADD-), 28 were $\mathrm{PiB}+\mathrm{CN}(\mathrm{CN}+), 29$ were $\mathrm{PiB}+\mathrm{MCI}(\mathrm{MCI}+)$, and 43 were $\mathrm{PiB}+\mathrm{ADD}(\mathrm{ADD}+)$. Figure $1 \mathrm{~b}$ shows the representative PiB-PET images of the study cohort $(n=353)$. The colors of the rainbow spectrum show the degree of $\mathrm{A} \beta$ deposition ( $\mathrm{PiB}$ retention, SUVR; red $\rightarrow$ purple, high $\rightarrow$ low, respectively).

\section{Proof-of-concept experiments for the effects of MPP on $A \beta$ quantification}

To verify the effect of MPP on A $\beta$ quantification, we used the synthetic $A \beta 42$ and plasma samples for the proof-ofconcept experiments (POC) (Fig. 2). When the same concentration of synthetic $A \beta 42$ (final concentration: $1 \mu \mathrm{M}$ of $\mathrm{A} \beta 42$ ) in the presence or absence of MPP was electrophoresed using western blotting, the $A \beta 42$ samples without 
Table 1 Demographic data of the complete study cohort for the main experiments (PiB- vs PiB+)

\begin{tabular}{llll}
\hline & Group (total, $n=353)$ & & \\
\hline Basic characteristic & PiB- $(n=253)$ & PiB+ $(n=100)$ & $P$ value ${ }^{a}$ \\
Global PiB deposition, mean \pm SEM & $1.11 \pm 0.004$ & $1.91 \pm 0.038$ & $<0.001$ \\
Clinical diagnosis, N/M/D & $187 / 50 / 16$ & $28 / 29 / 43$ & $<0.001^{\dagger}$ \\
Gender, male/female & $95 / 158$ & $38 / 62$ & $>0.05^{\dagger}$ \\
Age (years), mean \pm SEM & $69.94 \pm 0.5$ & $73.00 \pm 0.7$ & $<0.001$ \\
CDR, mean \pm SEM & $0.15 \pm 0.02$ & $0.5 \pm 0.04$ & $<0.001$ \\
MMSE $z$ score, ${ }^{\dagger}$ mean \pm SEM & $-0.13 \pm 0.07$ & $-1.91 \pm 0.20$ & $<0.001$ \\
Education, mean \pm SEM & $10.65 \pm 0.3$ & $10.82 \pm 0.5$ & $>0.05$ \\
ApoE4-positive, $n / N(\%)$ & $39 / 253(15 \%)$ & $57 / 100(57 \%)$ & $<0.001^{\dagger}$ \\
\hline
\end{tabular}

Details of clinical diagnosis and pathological states (CDR score, MMSE $z$ score, and global PiB deposition (SUVR)) of each subject are shown in Additional file 3 PiB Pittsburgh-compound B, SUVR standardized uptake value ratio, - or + PiB-PET positivity, MMSE Mini-Mental State Examination, CDR Clinical Dementia Rating, ApoE apolipoprotein $E$, SEM standard error of mean, $n$ number of subjects, $N / M / D$ cognitively normal/mild impairment/dementia

${ }^{\mathrm{a}} P$ value, significance by unpaired $t$-test except for clinical diagnosis, gender, and ApoE

${ }^{\mathrm{b}} \mathrm{A}$ revised value of the MMSE score with consideration for age, gender, and education level

'Pearson's chi-square test

MPP treatment showed variable band intensities among all four lanes of the blot, whereas MPP-treated A $\beta 42$ samples presented consistent band intensities in the blot (Fig. 2a; $P$ $<0.01, F$ test; for monomeric $\mathrm{A} \beta$, variance decreased by $34.75 \%^{2}$; for oligomeric $A \beta$, variance decreased by $16.11 \%^{2}$ ). Similarly, this phenomenon occurred when the original plasma sample was added (Fig. $2 \mathrm{~b} ; P<0.1$ and $P<0.01, F$ test; for monomeric $A \beta$, variance decreased by $3.16 \%$; for oligomeric $A \beta$, variance decreased by $1.86 \%{ }^{2}$ ). Next, we treated synthetic A $\beta 42$ with MPP and/or HSA and measured the $A \beta 42$ level using xMAP technology. Interestingly, the repetitively measured $A \beta 42$ concentrations showed dramatically reduced variance among their values for the MPP-treated sample set (Fig. 2c; $P<0.001$, without HSA, variance decreased by $1190.6 \mathrm{pg}^{2} / \mathrm{ml}^{2} ; P<0.01$ with HSA, variance decreased by $70.99 \mathrm{pg}^{2} / \mathrm{ml}^{2} ; F$ test). Furthermore, the repetitive measurement of plasma $A \beta 42$ and $A \beta 40$ showed significantly reduced variation (Fig. 2d; plasma A $342, P<0.05$, variance decreased by $22.70 \mathrm{pg}^{2} / \mathrm{ml}^{2}$; plasma A $\beta 40, P<0.01$, variance decreased by $1151.34 \mathrm{pg}^{2} / \mathrm{ml}^{2} ; F$ test). In addition, we identified whether MPP could inhibit the degradation of plasma $A \beta$ over time (from 0 to $24 \mathrm{~h}$ ) because a previous study reported that plasma sample storage at RT leads to a significant loss of measurable $A \beta$ peptide level [46]. For the human plasma samples, MPPtreated plasma $\mathrm{A} \beta 42$ (MPP-A $\beta 42)$ and MPP-A $\beta 40$ remained stable for $24 \mathrm{~h}$ whereas non-MPP-treated plasma A 422 (nMPP-A 342 ) levels decreased rapidly, and nMPPA $\beta 40$ levels fluctuated (Fig. $2 \mathrm{e}, P<0.05$, unpaired $t$ test at each time point). This result indicates that MPP has an effect on stabilizing plasma $A \beta$ for $24 \mathrm{~h}$.

\section{POC for the effects of MPP on the distinction among the subject groups}

To examine the correlation between the plasma $A \beta$ concentration and brain $A \beta$ deposition, plasma samples from 55 subjects $(20 \mathrm{CN}-, 12 \mathrm{MCI}+, 23 \mathrm{ADD}+$; see Additional file 4 for more detail) who received PiB-PET imaging were used for further analysis (Fig. 3a, b). nMPP-A $\beta 42$ and nMPP-A $\beta 42 / 40$ levels showed no significant intergroup differences among all groups. In contrast, MPP-A $\beta 42$ and MPP-A $\beta 42 / 40$ were significantly lower in $\mathrm{MCI}+$ subjects (MPP-A $\beta 42,39.76 \pm$ $3.26 \mathrm{pg} / \mathrm{ml}$; MPP-A $342 / 40,0.24 \pm 0.02)$ and ADD+ subjects (MPP-A $422,38.65 \pm 2.45 \mathrm{pg} / \mathrm{ml}$; MPP-A $342 / 40,0.25 \pm$ $0.02)$ compared with CN- subjects (MPP-A $\beta 42,56.98 \pm$ $3.57 \mathrm{pg} / \mathrm{ml}$; MPP-A $\beta 42 / 40,0.34 \pm 0.02$ ) (Fig. $3 \mathrm{a} ; \quad P<0.01$ and $P<0.001$, ANOVA followed by Tukey's multiple comparison test). Interestingly, when global $\mathrm{PiB}$ deposition values (SUVR) were plotted with plasma $A \beta$ concentration, MPP-A $\beta 42$ and MPP-A $\beta 42 / 40$ (Fig. 3b; MPP-A $\beta 42$, $P<0.001, \quad r=-0.47 ;$ MPP-A $\beta 42 / 40, \quad P<0.01, \quad r=-0.39$; Pearson's correlation) were more correlated with brain amyloid deposit than nMPP-A $\beta 42$ and nMPP-A $\beta 42 / 40$ (Fig. 3b; nMPP-A $\beta 42, P<0.05, r=-0.29$; nMPP-A $\beta 42 / 40$, $P=0.12, r=-0.21$; Pearson's correlation). Therefore, we suggest that the treatment of the plasma with MPP provides an improved detection method for stable and reliable plasma $A \beta$ level, and plasma $A \beta$ concentration might reflect the brain amyloid deposit.

MPP-A $\beta$ s reflect the pathological load of $A \beta$ in the brain In the POC, we demonstrated that MPP works efficiently to improve stability in the quantification of plasma $A \beta$. To examine further the association of MPP$\mathrm{A} \beta$ levels with the progression of $\mathrm{AD}$, we conducted the main experiments by increasing the number of subjects (overall 353 subjects: $187 \mathrm{CN}-, 50 \mathrm{MCI}-, 16$ ADD-, 28 $\mathrm{CN}+, 29 \mathrm{MCI}+$, and $43 \mathrm{ADD}+$; Fig. 4). Likewise with POC results, $\mathrm{CN}-$ subjects had higher MPP-A $\beta 42$ $(44.57 \pm 1.05 \mathrm{pg} / \mathrm{ml})$ concentration than ADD+ subjects $(37.50 \pm 1.72 \mathrm{pg} / \mathrm{ml}) \quad(P<0.05, \quad$ Fig. $4 \mathrm{a}, \quad$ left graph; 


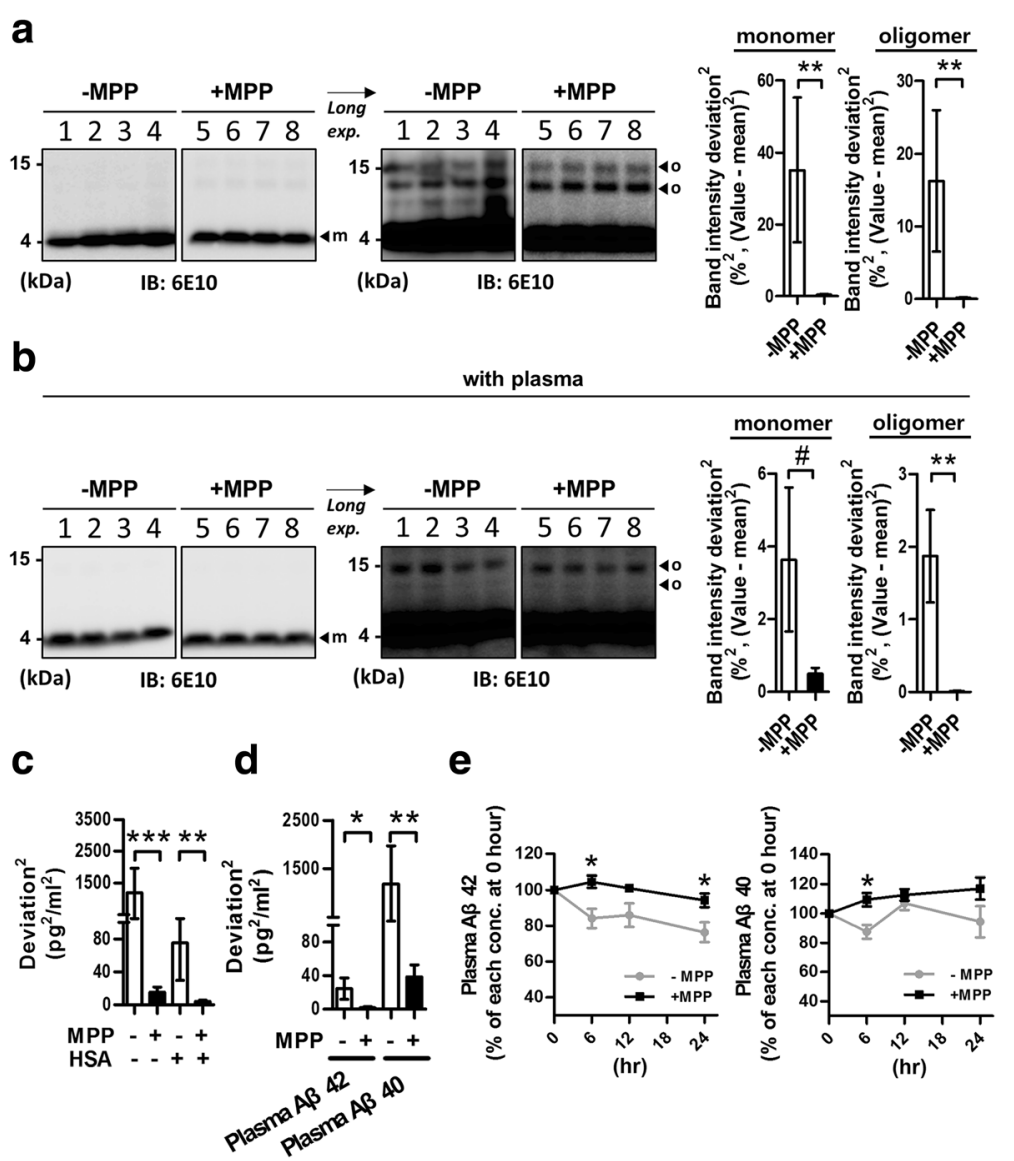

Fig. 2 POC for the effects of MPP on A $\beta$ quantification. a Gel electrophoresis for synthetic A 42 form assay. Twenty microliters of $8 \%$ DMSO in $1 \times$ PBS (-MPP) or $20 \mu \mathrm{l}$ of $8 \%$ MPP solution in $1 \times$ PBS (+MPP) was added to $20 \mu \mathrm{l}$ of $2 \mu \mathrm{M}$ Aß42 (final concentration, $1 \mu \mathrm{M}$; aliquots from the same pool, in separate $1.5-\mathrm{ml}$ tubes, $n=4)$, and the samples were electrophoresed. Band intensity squared deviation ((value - mean value $\left.)^{2}\right)$ indicates how far each point is from the mean value ${ }^{* *} P<0.01, F$ test to compare variances; each $\left.n=4\right)$. b Gel electrophoresis for synthetic $A \beta 42$ form assay with the original plasma sample. Twenty microliters of $8 \%$ DMSO and $25 \%$ plasma in $1 \times$ PBS (-MPP) or $20 \mu \mathrm{l}$ of $8 \%$ MPP and $25 \%$ plasma in $1 \times$ PBS (+MPP) was added to $20 \mu \mathrm{l}$ of $2 \mu \mathrm{M}$ Aß42 (final concentration, $1 \mu \mathrm{M}$; aliquots from the same pool, in separate 1.5-ml tubes, $n=$ $4)$, and the samples were electrophoresed. Band intensity squared deviation indicates how far each point is from the mean value $\left({ }^{\#} P<0.1\right.$, a trend toward significance; ${ }^{* *} P<0.01, F$ test to compare variances; each $n=4$ ). c Repetitive measurement of synthetic A 342 (aliquots from the same pool, in separate $1.5-\mathrm{ml}$ tubes, $n=6$ ) using XMAP technology, with or without MPP and/or HSA. HSA was used for mimicking blood plasma condition. Squared deviation indicates how far each point is from the mean value (**P<0.01 and ${ }^{* *} P<0.001, F$ test to compare variances). d Repetitive measurement (aliquots from the same pooled plasma, in separate $1.5-\mathrm{ml}$ tubes, $n=5$ ) of plasma $A \beta 42$ and $A \beta 40$ using XMAP technology, with or without MPP. Squared deviation indicates how far each point is from the mean value ${ }^{*} P<0.05$ and ${ }^{* *} P<0.01, F$ test to compare variances). e Quantification of plasma A 442 and A 40 in a time-dependent manner using XMAP technology, with or without $4 \%$ MPP solution in Bioplex sample diluent buffer ( $n=4$, independent individual plasma samples; ${ }^{*} P<0.05$, unpaired $t$ test for - MPP vs + MPP at each time point). $m$ monomeric $A \beta$; o oligomeric $A \beta, A \beta \beta$-amyloid, MPP mixture of protease inhibitors and phosphatase inhibitors, HSA human serum albumin

ANOVA followed by Tukey's multiple comparison test) and had higher levels of MPP-A $342 / 40(0.38 \pm 0.01)$ than both $\mathrm{MCI}+(0.29 \pm 0.02)$ and ADD+ $(0.28 \pm 0.01)$ subjects $(P<0.001$, Fig. 4a, right graph; ANOVA followed by Tukey's multiple comparison test). For further study, we performed a bivariate correlation analysis to test the relationship between MPP-A $\beta$ level and global PiB deposition (SUVR) indicating the degree of cortical $A \beta$ plaque deposition (Fig. $4 \mathrm{~b}$ and Table 2) and compared $\mathrm{PiB}-$ and $\mathrm{PiB}+$ subjects (Fig. 4c). First, we performed the
Pearson's correlation analysis for various groups. The MPP-A $\beta 40$ level and the MPP-A $\beta 42 / 40$ ratio showed significant correlation with global PiB deposition (SUVR) (MPP-A $\beta 40, P<0.0001, r=0.23$; MPP-A $\beta 42 / 40$ ratio, $P$ $<0.0001, r=-0.23$; Fig. $4 \mathrm{~b}$ and Table 2) in the complete study cohort (all, $n=353$ ). Furthermore, there were several significant correlations in many subgroups as well as in the overall study group. Both MPP-A $\beta 42(P<0.01$, $r=0.3479)$ and MPP-A $340(P<0.01, r=0.2950)$ levels were dramatically correlated with global $\mathrm{PiB}$ deposition 


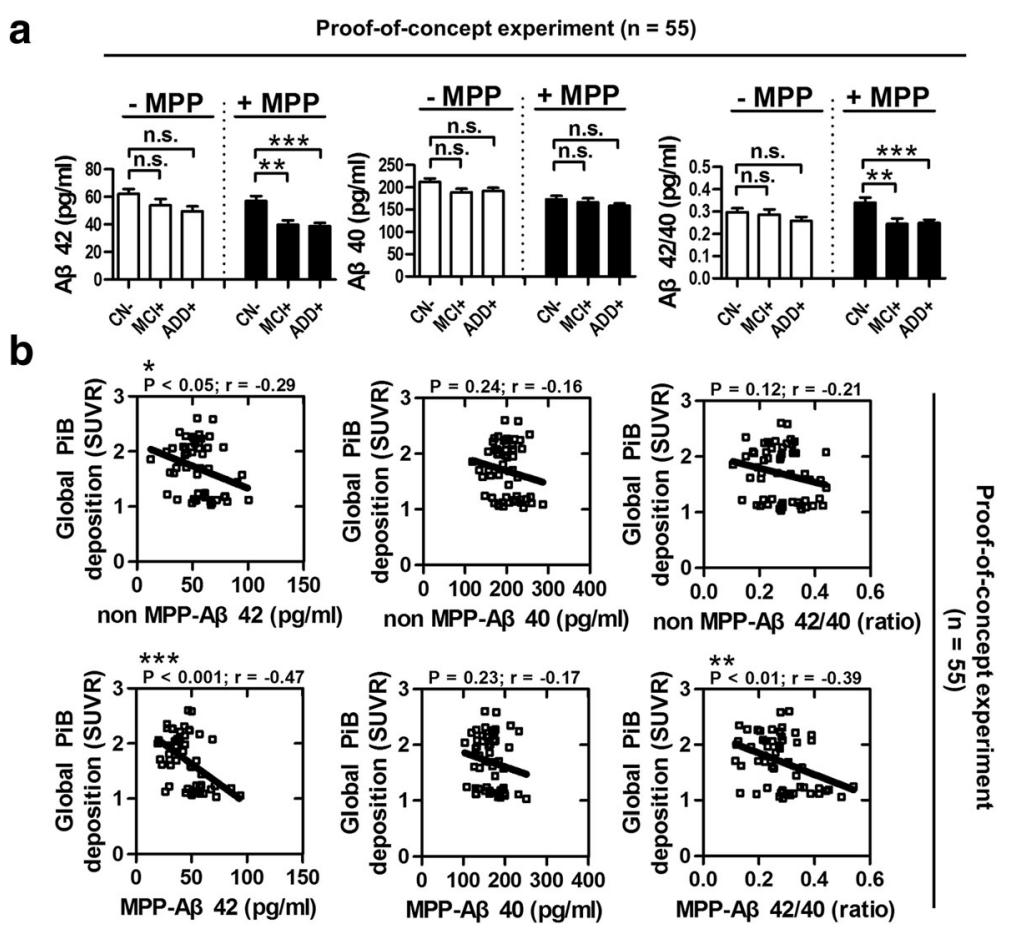

Fig. 3 POC for the effect of MPP on distinction between subjects. a Intergroup differences in the plasma A 3 concentration with or without $4 \%$ MPP solution using XMAP technology. MCI+ and ADD+ subjects show significantly decreased levels of MPP-Aß42 and MPP-A $42 / 40$ ratio compared with $C N$ - subjects ( ${ }^{* *} P<0.01$ and ${ }^{* *} P<0.001$ respectively; ANOVA followed by Tukey's multiple comparison test; $C N-, n=20 ; M C l+, n=12 ; A D D+, n=23 ;$ total subjects, $n=55$ ). $\mathbf{b}$ Correlation of global PiB deposition (SUVR) and MPP-ABs. MPP-A 442 level (*** $P<0.001, r=-0.47$; Pearson's correlation) and MPP-A $442 /$ 40 ratio ${ }^{* *} P<0.01, r=-0.39$; Pearson's correlation) are correlated with global PiB deposition (SUVR). $A \beta \beta$-amyloid, MPP mixture of protease inhibitors and phosphatase inhibitors, $M C$ I mild cognitive impairment, $A D D$ Alzheimer's disease dementia, CN cognitively normal, SUVR standard uptake value ratio, PiB Pittsburgh compound $\mathrm{B}_{1}-$ or + PiB negativity or positivity

(SUVR) in MCI subjects $(n=79)$. The MPP-A 440 level was significantly associated with global $\mathrm{PiB}$ deposition (SUVR) in nondemented subjects $(\mathrm{ND}=\mathrm{CN}$ plus MCI, $n=294) \quad(P<0.001, \quad r=0.2177), \quad$ in cognitively impaired subjects $(\mathrm{CI}=\mathrm{MCI}$ plus ADD, $n=138)(P<0.01$, $r=0.2272)$, and in $\mathrm{CN}$ subjects $(n=215)(P<0.05, r=$ $0.1479)$ (Table 2). The MPP-A $\beta 42 / 40$ ratio was correlated with global $\mathrm{PiB}$ deposition (SUVR) in ND subjects $(P<$ $0.01, r=-0.1654)$. Furthermore, the MPP-A $\beta 42 / 40$ ratio $(P=0.09, r=-0.1145)$ had a trend toward significant correlation with global $\mathrm{PiB}$ deposition (SUVR) in $\mathrm{CN}$ subjects (Table 2). This suggests that MPP-A $\beta$ levels reflect the state of $A \beta$ plaque deposition in the brain. Table 2 presents the detailed information of the correlation between global $\mathrm{PiB}$ deposition (SUVR) and MPP-A $\beta$ levels. Next, we found that PiB- subjects (CN- plus MCI- plus ADD-, $n=253$ ) had significantly different levels of MPP-A $\beta 40(118.70 \pm 2.09 \mathrm{pg} / \mathrm{ml})$ and MPP-A $\beta 42 / 40$ ratio $(0.36 \pm 0.01)$ in comparison with $\mathrm{PiB}+$ subjects $(\mathrm{CN}+$ plus $\mathrm{MCI}+$ plus $\mathrm{ADD}+, n=100$; $\mathrm{MPP}-$ $\mathrm{A} \beta 40, \quad 136.60 \pm 3.37 \mathrm{pg} / \mathrm{ml} ; \quad \mathrm{MPP}-\mathrm{A} \beta 42 / 40, \quad 0.30 \pm 0.01$ ) (Fig. 4c, $P<0.0001$, unpaired $t$ test). In addition, the MPP$\mathrm{A} \beta 40$ level and MPP-A $\beta 42 / 40$ ratio were dramatically different in $\mathrm{PiB}+\mathrm{ND}$ subjects (ND+, $n=57)$ (MPP-A $\beta 40$,
$134.80 \pm 4.10 \mathrm{pg} / \mathrm{ml} ; \mathrm{MPP}-\mathrm{A} \beta 42 / 40,0.31 \pm 0.01)$ compared with PiB- ND subjects (ND-, $n=237)(\mathrm{MPP}-\mathrm{A} \beta 40$, $117.80 \pm 2.10 \quad \mathrm{pg} / \mathrm{ml} ; \quad$ MPP-A $\beta 42 / 40, \quad 0.36 \pm 0.01)$ (Fig. $4 \mathrm{~d}, P<0.01$ and $P<0.0001$, unpaired $t$ test). Furthermore, $\mathrm{MCI}+$ subjects showed significantly higher MPP-A $\beta 42 \quad(39.46 \pm 1.88 \mathrm{pg} / \mathrm{ml})$ and MPP-A $\beta 40$ $(140.00 \pm 6.86 \mathrm{pg} / \mathrm{ml})$ levels than MCI- subjects (MPP-A $\beta 42, \quad 32.03 \pm 1.37 \mathrm{pg} / \mathrm{ml} ; \quad$ MPP-A $\beta 40,114.30 \pm$ $6.86 \mathrm{pg} / \mathrm{ml})(P<0.01$, Fig. 4a, left and middle graphs, unpaired $t$ test). Moreover, $\mathrm{CN}+$ subjects showed significantly lower values of MPP-A $\beta 42 / 40$ ratio $(0.33 \pm 0.02)$ than $\mathrm{CN}-$ subjects $(0.39 \pm 0.01)(P<0.05$, Fig. 4 a, right graph, unpaired $t$ test) and higher values of MPPA $\beta 40 \quad(129.40 \pm 4.26 \mathrm{pg} / \mathrm{ml})$ than $\mathrm{CN}-$ subjects $(118.80 \pm 2.24 \mathrm{pg} / \mathrm{ml})(P=0.08$, a trend toward significance; Fig. 4a, middle graph, unpaired $t$ test).

\section{Prediction of cerebral amyloid deposition based on MPP- $A \beta 42 / 40$ ratio}

To apply these analyzed results (Fig. 4) to practical use, we performed a subsequent logistic regression and ROC curve analysis using independent variables (Fig. 5). Multiple variables (MPP-A $\beta$ s and ApoE genotype) and control variables (gender and age) were mixed by logistic 


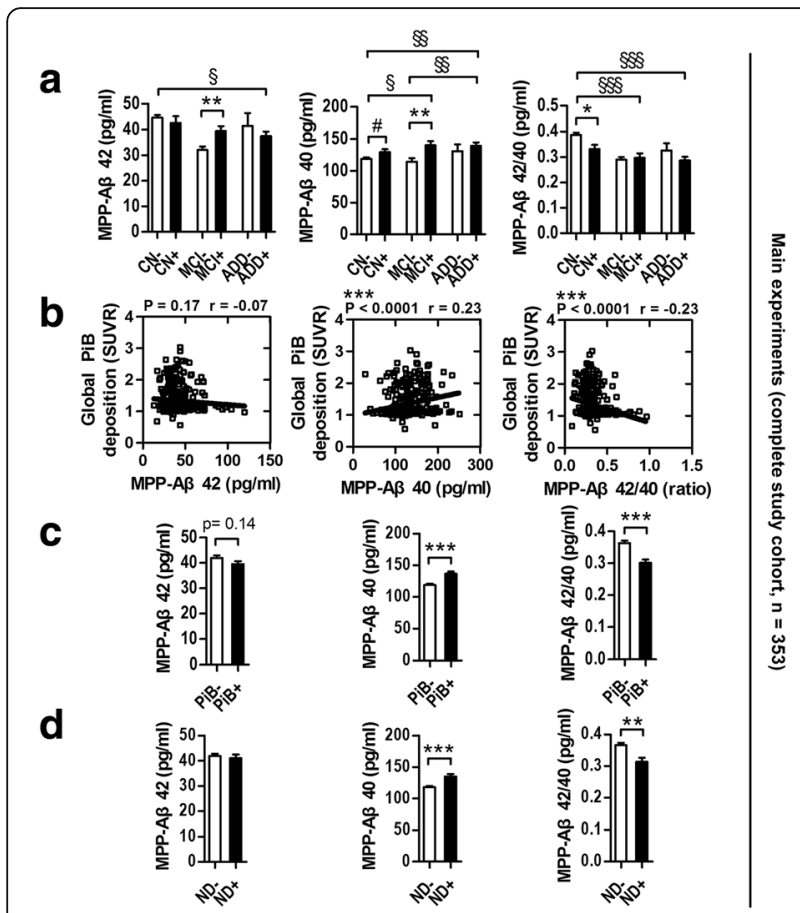

Fig. 4 MPP-A $A$ s reflect the pathological load of $A \beta$ in the brain. a Intergroup differences of MPP-A $\beta$ levels using XMAP technology $\left({ }^{*} P<0.05\right.$ and ${ }^{* *} P<0.01$, unpaired $t$ test; ${ }^{\S} P<0.05$, ${ }^{\S} P P<0.01$, and $\S \S \S<0.001$, ANOVA followed by Tukey's multiple comparison test; ${ }^{\sharp} P<0.10$, unpaired $t$ test, trend toward significance; $C N-, n=187$, $\mathrm{CN}+, n=28, \mathrm{MCl}-, n=50, \mathrm{MCl}+, n=29, \mathrm{ADD}-, n=16, \mathrm{ADD}+, n=43$; total subjects $n=353$ ). $\mathbf{b}$ Correlation of global PiB deposition (SUVR) and MPP-Aßs ( $n=353$, ${ }^{* * *} P<0.0001$; Pearson's correlation). c, d MPP-A $\beta 42$, MPP-A $\beta 40$, and MPP-A $42 / 40$ levels in ND- $(n=237 ; C N-$ and $\mathrm{MCl}-), \mathrm{ND}+(n=57 ; \mathrm{CN}+$ and $\mathrm{MCl}+), \mathrm{PiB}-(n=253 ; \mathrm{CN}-, \mathrm{MCl}-$, and $\mathrm{ADD}-)$, and $\mathrm{PiB}+(n=100 ; \mathrm{CN}+, \mathrm{MCl}+$, and $\mathrm{ADD}+)\left({ }^{* *} P<0.01\right.$, and ${ }^{* * *} P<0.001$, unpaired $t$ test). $A \beta \beta$-amyloid, MPP mixture of protease inhibitors and phosphatase inhibitors, $M C l$ mild cognitive impairment, ADD Alzheimer's disease dementia, CN cognitively normal, SUVR standard uptake value ratio, PiB Pittsburgh compound $\mathrm{B}_{1}-$ or + PiB negativity or positivity, ND nondemented regression analysis, and the predicted probabilities were used to assess the discrimination power (ROC curve analysis) for the prediction of PiB-PET positivity. The classification variable was ND- vs ND+ (Fig. 5a) or PiB- vs $\mathrm{PiB}+$ (Fig. 5b). The combination of MPP-A $\beta 42 / 40$ and control variables (gender and age) increased the area under curve (AUC) values (ND- vs ND+, 0.695; $\mathrm{PiB}-$ vs $\mathrm{PiB}+, 0.682$ ) compared with MPP-A $\beta 42 / 40$ alone (ND- vs $\mathrm{ND}+, 0.639$; $\mathrm{PiB}-\mathrm{vs} \mathrm{PiB}+, 0.668$ ) (Fig. 5 and Table 3). Furthermore, AUC values were further enhanced on adding the ApoE variable (ND- vs ND+, 0.783; $\mathrm{PiB}-$ vs $\mathrm{PiB}+$, 0.799). Table 3 presents more detail about the results of logistic regression followed by ROC curve analysis.

\section{Discussion}

Plasma $A \beta$ levels are believed unstable, and many plasma proteins such as HSA, TTR, and others are believed to interrupt the detection of $A \beta[24,26]$. Furthermore, the plasma contains diverse proteases released from neutrophils and phagocytes [40, 47, 48]. Although the plasma contains several protease inhibitors such as $\alpha_{2}$-macroglobulin, $\alpha_{1}$-protease inhibitor, and plasminogen activator inhibitor-1 (PAI-1) [49-52], these are not sufficient for the preservation of the integrity of plasma proteins during the storage of samples at $4{ }^{\circ} \mathrm{C}$ or RT [53]. Moreover, Kumar et al. [31] reported that phosphorylation of $A \beta$ at Ser- 8 inhibited the degradation of monomeric $A \beta$. Accurate analysis with plasma requires a high quality of starting samples; however, there have been no previous attempts to stabilize the plasma $A \beta$ by chemical treatment. We hypothesized that protease inhibitors and phosphatase inhibitors might have a role in reducing $A \beta$ degradation because the $A \beta$ sequence contains many possible proteases and phosphorylation sites [30,31]. We found that the variation in $A \beta$ concentration through repetitive measurement (using western blot and Luminex system) was significantly reduced by MPP treatment in a variety of settings including $A \beta$ with pure sample diluent buffer $(1 \times$ PBS or Bioplex buffer)

Table 2 Detailed information of the correlation between brain amyloid deposition (global PiB deposition (SUVR)) and MPP-Aßs

\begin{tabular}{|c|c|c|c|c|c|c|c|c|}
\hline & $\begin{array}{l}\mathrm{CN} \\
(n=215)\end{array}$ & $\begin{array}{l}\mathrm{MCl} \\
(n=79)\end{array}$ & $\begin{array}{l}\text { ADD } \\
(n=59)\end{array}$ & $\begin{array}{l}\text { ND } \\
(n=294)\end{array}$ & $\begin{array}{l}\mathrm{Cl} \\
(n=138)\end{array}$ & $\begin{array}{l}\text { PiB- } \\
(n=253)\end{array}$ & $\begin{array}{l}\mathrm{PiB}+ \\
(n=100)\end{array}$ & $\begin{array}{l}\text { All } \\
(n=353)\end{array}$ \\
\hline \multirow[t]{2}{*}{ MPP-Aß42 } & $P=0.7982$ & ${ }^{* *} P<0.01$ & $P=0.3132$ & $P=0.9827$ & $P=0.1125$ & $P=0.9750$ & $P=0.7965$ & $P=0.1776$ \\
\hline & $r=0.0175$ & $r=0.3479$ & $r=-0.1336$ & $r=-0.0012$ & $r=0.1357$ & $r=0.0020$ & $r=-0.0261$ & $r=-0.0719$ \\
\hline \multirow[t]{2}{*}{ MPP-Aß40 } & ${ }^{*} P=0.0301$ & ${ }^{* *} P<0.01$ & $P=0.6639$ & ${ }^{* *} P<0.001$ & ${ }^{* *} P<0.01$ & $P=0.8155$ & $P=0.2436$ & ${ }^{* * * *} P<0.0001$ \\
\hline & $r=0.1479$ & $r=0.2950$ & $r=0.0578$ & $r=0.2177$ & $r=0.2272$ & $r=-0.0147$ & $r=0.1177$ & $r=0.2309$ \\
\hline \multirow[t]{2}{*}{ MPP-A $\beta 42 / 40$} & ${ }^{\#} P=0.0940$ & $P=0.6395$ & $P=0.2868$ & ${ }^{* *} P<0.01$ & $P=0.6488$ & $P=0.7416$ & $P=0.4437$ & ${ }^{* * * *} P<0.0001$ \\
\hline & $r=-0.1145$ & $r=0.0535$ & $r=-0.1410$ & $r=-0.1654$ & $r=-0.0391$ & $r=-0.0208$ & $r=-0.0775$ & $r=-0.2280$ \\
\hline
\end{tabular}

SUVR standard uptake value ratio, MPP-A $\beta$ MPP-treated plasma $\beta$-amyloid, $C N$ cognitively normal, $M C I$ mild cognitive impairment, $A D D$ Alzheimer's disease dementia, $N D$ nondemented group (CN plus $\mathrm{MCl}$ ), $\mathrm{Cl}$ cognitively impaired group ( $\mathrm{MCl}$ plus $\mathrm{ADD}$ ), PiB- or PiB+ subjects with negative or positive amyloid deposition, $A$ ll complete study cohort

${ }^{*} P<0.05$, ${ }^{* *} P<0.01,{ }^{* * *} P<0.001$, and ${ }^{* * * *} P<0.0001$ and Pearson $r$ values by Pearson's correlation analysis (two-tailed)

${ }^{\#} P<0.10$, trend toward significance 
a

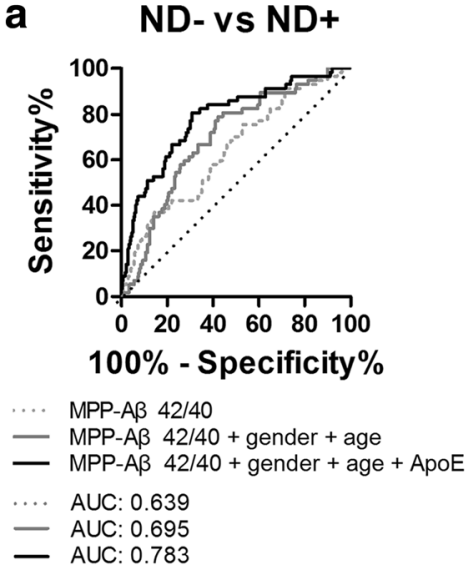

b PiB-vs PiB+

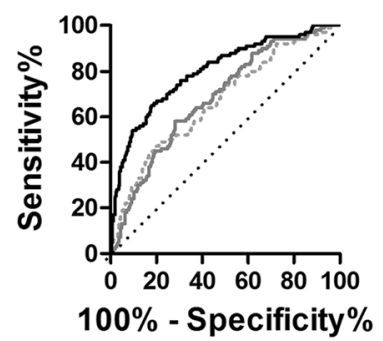

… MPP-A $42 / 40$

- MPP-A $42 / 40+$ gender + age

- MPP-A $\beta$ 42/40 + gender + age + ApoE

… AUC: 0.668

- AUC: 0.682

Fig. 5 Logistic regression model and ROC curve analysis for PiB-PET prescreening ROC curve model using a combination of variables (MPP-A 3 , gender, age, and ApoE types) following the logistic regression analysis comparing (a) ND- and ND+ or (b) PiB- and PiB+. See details in Table 3. PiB Pittsburgh compound B, - or + PiB negativity or positivity, ND nondemented, ApoE apolipoprotein E, MPP-A $\beta$ MPP-treated plasma $\beta$-amyloid, AUC area under curve

(Fig. 2a, c), with plasma mimic buffer using HSA (Fig. 2c) [43], and with diluent buffer containing the original plasma sample (Fig. 2b, d). The purpose of repetitively measuring experiments (Fig. 2a-d) was to investigate whether the same samples distributed in different tubes show the same concentration value. Because of the instability of $A \beta$ peptides, the detected values might have changed (during the incubation for $30 \mathrm{~min}$ at RT) depending on the independent tubes, even though they were same samples. As expected, without MPP treatment, the detected values fluctuated; however, when we treated samples with MPP, the detected values were quite similar to each other. This indicates that MPP allows us to control the unavoidable experimental errors (especially unexpected time delay) that occur during the experiment procedure. Furthermore MPP-treated plasma $A \beta 42$ and $A \beta 40$ (MPP-A $\beta 42$ and MPP-A $\beta 40$ ) maintained their concentration efficiently for $24 \mathrm{~h}$ whereas non-MPP-treated plasma $\mathrm{A} \beta 42$ (nMPP-A $\beta 42$ ) levels decreased rapidly, and nMPP-A $\beta 40$ levels fluctuated with incubation times (Fig. 2e). These results indicate that MPP might have a stabilizing effect on the quantification of plasma $A \beta s$. Hence, we next differentiated $\mathrm{PiB}-(\mathrm{CN}-, \mathrm{MCI}-$, and $\mathrm{ADD}-)$ vs $\mathrm{PiB}+(\mathrm{CN}+, \mathrm{MCI}$ + , and $\mathrm{ADD}+$ ) subjects using MPP-A $\beta$ s. Interestingly, although not all comparisons were statistically significant, most cases comparing $\mathrm{PiB}-\mathrm{vs} \mathrm{PiB}+$ had the same patterns for MPP-A $\beta 40$ level and MPP-A $\beta 42 / 40$ ratio (MPP-A $\beta 40, \mathrm{CN}-<\mathrm{CN}+, \mathrm{MCI}-<\mathrm{MCI}+$, and $\mathrm{ADD}-<$ $\mathrm{ADD}+$; $\mathrm{MPP}-\mathrm{A} \beta 42 / 40, \mathrm{CN}->\mathrm{CN}+$, and $\mathrm{ADD}->$ ADD+; Fig. 4a). Hence, we compared the subjects again as ND- vs ND+ and $\mathrm{PiB}-$ vs $\mathrm{PiB}+$. The MPPA $\beta 40$ level was dramatically increased, and the MPP-A $\beta 42 / 40$ ratio was significantly reduced in ND+ and $\mathrm{PiB}+$ in comparison with $\mathrm{ND}-$ and $\mathrm{PiB}-$ subjects respectively (Fig. 4c, d). This indicates that MPP-A $\beta$ might be a

Table 3 Detailed information of ROC curve analysis

\begin{tabular}{|c|c|c|c|c|c|c|}
\hline Panel & AUC & Sensitivity (\%) & Specificity (\%) & $P$ value & Cutoff criterion & $95 \% \mathrm{Cl}$ of $\mathrm{AUC}$ \\
\hline \multicolumn{7}{|l|}{ ND- vs ND+ } \\
\hline MPP-Aß42/40 & 0.639 & 71.8 & 51.5 & $<0.0001$ & $>0.1871$ & $0.559-0.719$ \\
\hline MPP-Aß42/40 + age + gender & 0.695 & 79.0 & 57.8 & $<0.0001$ & $>0.1864$ & $0.622-0.767$ \\
\hline $\mathrm{MPP}-\mathrm{A} \beta 42 / 40+$ age + gender $+\mathrm{ApoE}$ & 0.783 & 80.7 & 69.2 & $<0.0001$ & $>0.1730$ & $0.715-0.852$ \\
\hline \multicolumn{7}{|l|}{ PiB- vs PiB+ } \\
\hline MPP-Aß42/40 & 0.668 & 71.0 & 52.2 & $<0.0001$ & $>0.2731$ & $0.605-0.731$ \\
\hline MPP-Aß42/40 + age + gender & 0.682 & 71.0 & 54.2 & $<0.0001$ & $>0.2759$ & $0.622-0.741$ \\
\hline $\mathrm{MPP}-\mathrm{A} \beta 42 / 40+$ age + gender $+\mathrm{ApoE}$ & 0.799 & 78.0 & 66.8 & $<0.0001$ & $>0.2230$ & $0.746-0.852$ \\
\hline
\end{tabular}

$A p o E$ Apolipoprotein $\mathrm{E}, A \cup C$ area under curve, MPP mixture of protease inhibitors and phosphatase inhibitors, $C l$ confidence interval, $R O C$ receiver operating characteristic, - or + PiB-PET positivity, ND- PiB-PET-negative cognitively normal $(C N)$ and PiB-PET-negative subjects with mild cognitive impairment (MCl), ND+ PiB-PET-positive CN and PiB-PET-positive MCl, PiB- grouped $\mathrm{CN}-, \mathrm{MCl}-$, and ADD-, PiB+ grouped CN+, $\mathrm{MCl}+$, and ADD+ 
potential biomarker to predict $A \beta$ deposition in the brain. Although the age of subjects who were $\mathrm{PiB}+$ was relatively higher than that of $\mathrm{PiB}$ - subjects (Table 1), the significant difference of MPP-A $\beta$ s between $\mathrm{PiB}+$ and $\mathrm{PiB}-$ subjects (MPP-A $\beta 40$ increased and MPP-A $\beta 42 / 40$ decreased in $\mathrm{PiB}+$, compared with $\mathrm{PiB}-$; Fig. 4c) was not due to the effects of aging because comparing young-middleaged controls (YC, cognitively normal subjects with age 20-55 years, $n=61$ ) vs $\mathrm{CN}-$ subjects showed completely opposite trends to $\mathrm{PiB}-\mathrm{vs} \mathrm{PiB}+$ subjects, regarding MPP-A $\beta$ s (see Additional files 5 and 6 for more detail).

Even in cases where the MPP-A $\beta 42 / 40$ ratio was dramatically different between $\mathrm{PiB}-$ and $\mathrm{PiB}+$ subjects, it was insufficient to be used as a variable for ROC curve analysis to discriminate ND- vs ND+ or $\mathrm{PiB}-$ vs $\mathrm{PiB}+$ subjects (ND- vs ND+, AUC 0.639 with $71.8 \%$ sensitivity and $51.5 \%$ specificity; PiB- vs PiB+, AUC 0.668 with $71.0 \%$ sensitivity and $52.2 \%$ specificity; Fig. 5 and Table 3). Using the combination of additional risk factors (gender, age, and ApoE types) reported previously [54, 55], we conducted the logistic regression analysis followed by ROC curve analysis to establish the screening model for cerebral amyloid deposition. We showed that the combination of MPP$\mathrm{A} \beta 42 / 40$ ratio, gender, and age had a stronger discrimination power (ND- vs ND+, AUC 0.695 with 79.0\% sensitivity and $57.8 \%$ specificity; $\mathrm{PiB}-$ vs $\mathrm{PiB}+$, AUC 0.682 with $71.0 \%$ sensitivity and $54.2 \%$ specificity; Fig. 5 and Table 3) than the MPP-A $\beta 42 / 40$ level alone. Furthermore, we observed that AUC was increased further by ApoE variable (ND- vs ND+, AUC 0.783 with $80.7 \%$ sensitivity and $69.2 \%$ specificity; PiB- vs PiB+, AUC 0.799 with $78.0 \%$ sensitivity and $66.8 \%$ specificity; Fig. 5 and Table 3).

These results are in line with several previous reports that showed an interrelationship between plasma $A \beta 42 /$ 40 ratio and dementia $[56,57]$. However, this study is the first to stabilize the quantification of plasma $A \beta$ by the treatment of chemicals and predict the PiB-PET positivity by classifying the subjects into two large groups, ND- vs $\mathrm{ND}+$ subjects and $\mathrm{PiB}-$ vs $\mathrm{PiB}+$ subjects, regardless of the stage of cognitive impairment. We showed a distinct relationship between MPP-A $\beta$ s and pathological $\mathrm{AD}$-related $\mathrm{A} \beta$ burden in the brain. In conclusion, these results suggest that our model using MPP-A $A s$ and other factors could be utilized as a prescreening tool to predict cerebral $\mathrm{A} \beta$ deposition.

\section{Conclusions}

The treatment of the plasma with a mixture of protease inhibitors and phosphatase inhibitors (MPP) provides an improved detection method for reliable plasma $A \beta$ level, and MPP-A $\beta$ s showed a correlation with $A \beta$ burden in the brain.

\section{Additional files}

Additional file 1: is a figure showing the experimental flow chart.
(DOCX $37 \mathrm{~kb})$

Additional file $\mathbf{2}$ is a table presenting demographic data of the complete study cohort. (DOCX $58 \mathrm{~kb}$ )

Additional file 3: is a figure showing clinical and pathological states of the study cohort: (a) SUVR of subjects ( ${ }^{*} P<0.05$ and ${ }^{* * *} P<0.001$, ANOVA followed by Tukey's multiple comparison test), (b) MMSE $z$ score $\left({ }^{*} P<0.05\right.$, ANOVA followed by Tukey's multiple comparison test), and (c) CDR score (***P $<0.001$, ANOVA followed by Tukey's multiple comparison test). (DOCX $67 \mathrm{~kb}$ )

Additional file 4: is a table presenting demographic data of subjects for Proof-of-concept (POC) experiments in the study. (XLSX $11 \mathrm{~kb}$ )

Additional file 5: is a figure showing MPP-A $\mathrm{Ss}$ and aging: (a) $C N-$ show significantly higher MPP-A 342 and MPP-A $342 / 40$ ratio than $Y C{ }^{* * *} P<0.001$, unpaired $t$ test) and (b) MPP-A 42 and MPP-A $342 / 40$ ratio show significant association with aging ( ${ }^{* * *} P<0.0001, r=0.40$ for MPP-A $\beta 42 ;{ }^{* *} P<0.0001$, $r=0.33$ for MPP-A $42 / 40$ ratio; Pearson's correlation). (XLSX 11 kb)

Additional file 6: is a table presenting demographic data of youngmiddle-aged controls. (XLSX $10 \mathrm{~kb}$ )

\section{Abbreviations}

ADD: Alzheimer's disease dementia; AUC: Area under curve; A $\beta$ : $\beta$-Amyloid; CN: Cognitively normal; MCl: mild cognitive impairment; MMSE: Mini-Mental State Examination; MPP: Mixture of protease inhibitors and phosphatase inhibitors; MPP-Aß: MPP-treated plasma AB; ND-: Nondemented PiB-PET-negative; ND+: Nondemented PiB-PET-positive; PiB-: Negative amyloid deposition; PiB+: Positive amyloid deposition; PiB-PET: Pittsburgh-compound B positron emission tomography; POC: Proof-of-concept experiments; SUVR: Standardized uptake value ratio

\section{Acknowledgements}

The authors sincerely thank the patients and volunteers for their participation in this study. They are grateful to the staff of Department of Neuropsychiatry in Clinical Research Institute of Seoul National University Hospital, Department of Neuropsychiatry in Ulsan University Hospital, and Department of Nuclear Medicine in Seoul Metropolitan Government-Seoul National University Boramae Medical Center for their contribution and collaboration.

\section{Funding}

This work was supported by grants from NRF (2015R1A2A1A05001794, 2014M3C-7A1046047, MRC (2011-0030738)), by an SNU Medical School Basic-clinical joint program grant (800-20130066), and by the Education and Research Encouragement Fund of SNU Hospital for IHM-J. This study was also supported by a grant from NRF (2014M3C7A1046042) and an SNU Medical School Basic-clinical joint program grant (800-20130067) for DYL. Finally, this study was supported by a grant from NRF (2015R1C1A2A01053545) for $\mathrm{S}-\mathrm{HH}$.

Availability of data and materials Not applicable.

\section{Authors' contributions}

$J-C P, S-H H, H J C$, and $H \mathrm{HM}-J$ designed the study. MSB, DHY, YMC, and DYL obtained blood samples from the subjects and collected the cognitive and PiBPET data. J-CP, SJK, EHK, and SJW separated and aliquoted the human plasma. PiB-PET scan data were obtained, collected, and analyzed by YKK, $M S B, D H Y$, and DYL. J-CP, HJC, and ESJ performed all experiments measuring the levels of A $\beta$ with or without MPP. J-CP, HJC, and IHM-J interpreted the data and wrote the paper. IHM-J and DYL examined the earlier draft of the manuscript in detail and edited it. J-CP managed and analyzed all other data. IHM-J and DYL had full access to all of the data in the study and take responsibility for the integrity of the data and the accuracy of the data analysis. All authors read and approved the final manuscript.

\section{Competing interests}

The authors declare that they have no competing interests. 


\section{Consent for publication}

Not applicable.

\section{Ethics approval and consent to participate}

This work was approved by the Institutional Review Board (IRB) of the Seoul National University Hospital, South Korea, and the subjects or their legal representatives gave their written informed consent.

\section{Publisher's Note}

Springer Nature remains neutral with regard to jurisdictional claims in published maps and institutional affiliations.

\begin{abstract}
Author details
'Department of Biochemistry and Biomedical Sciences, Seoul National University, College of Medicine, 103 Daehak-ro, Jongno-gu, Seoul 110-799, South Korea. ${ }^{2}$ Neuroscience Research Institute, Seoul National University, College of Medicine, 103 Daehak-ro, Jongno-gu, Seoul 110-799, South Korea. ${ }^{3}$ Institute of Human Behavioral Medicine, Medical Research Center Seoul National University, Seoul 110-799, South Korea. ${ }^{4}$ Department of Neuropsychiatry, University of Ulsan College of Medicine, Ulsan University Hospital, Ulsan 682-714, South Korea. ${ }^{5}$ Department of Nuclear Medicine, Seoul Metropolitan Government-Seoul National University Boramae Medical Center, Seoul 156-707, South Korea. ${ }^{6}$ Department of Neuropsychiatry, Seoul National University Hospital, 101 Daehak-ro, Jongno-gu, Seoul 110-744, South Korea. ${ }^{7}$ Department of Psychiatry, Seoul National University College of Medicine, 101 Daehak-ro, Jongno-gu, Seoul 110-744, South Korea.
\end{abstract}

\section{Received: 27 December 2016 Accepted: 23 February 2017}

\section{Published online: 22 March 2017}

\section{References}

1. Serrano-Pozo A, Frosch MP, Masliah E, Hyman BT. Neuropathological alterations in Alzheimer disease. Cold Spring Harb Perspect Med. 2011;1:a006189.

2. Song H, Chang YJ, Moon M, Park SK, Tran PT, Hoang VH, Lee J, Mook-Jung I. Inhibition of glutaminyl cyclase ameliorates amyloid pathology in an animal model of Alzheimer's disease via the modulation of gamma-secretase activity. J Alzheimers Dis. 2015;43:797-807.

3. Jansen WJ, Ossenkoppele R, Knol DL, Tijms BM, Scheltens P, Verhey FR, Visser PJ, Amyloid Biomarker Study G, Aalten P, Aarsland D, et al. Prevalence of cerebral amyloid pathology in persons without dementia: a metaanalysis. JAMA. 2015;313:1924-38.

4. Sheng M, Sabatini BL, Sudhof TC. Synapses and Alzheimer's disease. Cold Spring Harb Perspect Biol. 2012:4:a005777

5. Yiannopoulou KG, Papageorgiou SG. Current and future treatments for Alzheimer's disease. Ther Adv Neurol Disord. 2013;6:19-33.

6. Cataldo JK, Prochaska JJ, Glantz SA. Cigarette smoking is a risk factor for Alzheimer's Disease: an analysis controlling for tobacco industry affiliation. J Alzheimers Dis. 2010;19:465-80

7. Malouf M, Grimley EJ, Areosa SA. Folic acid with or without vitamin B12 for cognition and dementia. Cochrane Database Syst Rev. 2003:4:CD004514.

8. Pillai JA, Verghese J. Social networks and their role in preventing dementia. Indian J Psychiatry. 2009;51 Suppl 1:S22-8.

9. Skoog I, Gustafson D. Update on hypertension and Alzheimer's disease. Neurol Res. 2006;28:605-11.

10. Solfrizzi V, Panza F, Frisardi V, Seripa D, Logroscino G, Imbimbo BP, Pilotto A. Diet and Alzheimer's disease risk factors or prevention: the current evidence. Expert Rev Neurother. 2011;11:677-708.

11. Radak Z, Hart N, Sarga L, Koltai E, Atalay M, Ohno H, Boldogh I. Exercise plays a preventive role against Alzheimer's disease. J Alzheimers Dis. 2010;20:777-83.

12. Kang S, Jeong H, Baek JH, Lee SJ, Han SH, Cho HJ, Kim H, Hong HS, Kim YH, Yi EC, et al. PiB-PET imaging-based serum proteome profiles predict mild cognitive impairment and Alzheimer's disease. J Alzheimers Dis. 2016;53:1563-76.

13. Klunk WE, Engler H, Nordberg A, Wang Y, Blomqvist G, Holt DP, Bergstrom M, Savitcheva I, Huang GF, Estrada S, et al. Imaging brain amyloid in Alzheimer's disease with Pittsburgh Compound-B. Ann Neurol. 2004;55:306-19.

14. Hampel H, Teipel SJ, Fuchsberger T, Andreasen N, Wiltfang J, Otto M, Shen Y, Dodel R, Du Y, Farlow M, et al. Value of CSF beta-amyloid1-42 and tau as predictors of Alzheimer's disease in patients with mild cognitive impairment. Mol Psychiatry. 2004;9:705-10.
15. Irizarry MC. Biomarkers of Alzheimer disease in plasma. NeuroRx. 2004;1:226-34.

16. Bisaccia E, Berger C, DiSpaltro FX, Armus S, Cahill C, Klainer A. Viral-specific immunization in AIDS-related complex by photopheresis. Ann N Y Acad Sci. 1991;636:321-30.

17. Lewczuk P, Kornhuber J, Vanmechelen E, Peters O, Heuser I, Maier W, Jessen F, Burger K, Hampel H, Frolich L, et al. Amyloid beta peptides in plasma in early diagnosis of Alzheimer's disease: a multicenter study with multiplexing. Exp Neurol. 2010;223:366-70.

18. Pesaresi M, Lovati C, Bertora P, Mailland E, Galimberti D, Scarpini E, Quadri P, Forloni G, Mariani C. Plasma levels of beta-amyloid (1-42) in Alzheimer's disease and mild cognitive impairment. Neurobiol Aging. 2006;27:904-5.

19. Graff-Radford NR, Crook JE, Lucas J, Boeve BF, Knopman DS, Ivnik RJ, Smith GE, Younkin LH, Petersen RC, Younkin SG. Association of low plasma Abeta42/Abeta40 ratios with increased imminent risk for mild cognitive impairment and Alzheimer disease. Arch Neurol. 2007;64:354-62.

20. Yaffe K, Weston A, Graff-Radford NR, Satterfield S, Simonsick EM, Younkin SG, Younkin LH, Kuller L, Ayonayon HN, Ding J, Harris TB. Association of plasma beta-amyloid level and cognitive reserve with subsequent cognitive decline. JAMA. 2011;305:261-6.

21. Blasko I, Jellinger K, Kemmler G, Krampla W, Jungwirth S, Wichart I, Tragl KH, Fischer P. Conversion from cognitive health to mild cognitive impairment and Alzheimer's disease: prediction by plasma amyloid beta 42, medial temporal lobe atrophy and homocysteine. Neurobiol Aging. 2008;29:1-11.

22. Fukumoto $H$, Tennis M, Locascio JJ, Hyman BT, Growdon JH, Irizarry MC. Age but not diagnosis is the main predictor of plasma amyloid beta-protein levels. Arch Neurol. 2003;60:958-64.

23. van Oijen M, Hofman A, Soares HD, Koudstaal PJ, Breteler MM. Plasma Abeta(1-40) and Abeta(1-42) and the risk of dementia: a prospective casecohort study. Lancet Neurol. 2006;5:655-60.

24. Han SH, Jung ES, Sohn JH, Hong HJ, Hong HS, Kim JW, Na DL, Kim M, Kim $\mathrm{H}, \mathrm{Ha} \mathrm{HJ}$, et al. Human serum transthyretin levels correlate inversely with Alzheimer's disease. J Alzheimers Dis. 2011;25:77-84.

25. Han SH, Park JC, Mook-Jung I. Amyloid beta-interacting partners in Alzheimer's disease: from accomplices to possible therapeutic targets. Prog Neurobiol. 2016;137:17-38

26. Kuo YM, Kokjohn TA, Kalback W, Luehrs D, Galasko DR, Chevallier N, Koo EH, Emmerling MR, Roher AE. Amyloid-beta peptides interact with plasma proteins and erythrocytes: implications for their quantitation in plasma. Biochem Biophys Res Commun. 2000;268:750-6.

27. Reyes Barcelo AA, Gonzalez-Velasquez FJ, Moss MA. Soluble aggregates of the amyloid-beta peptide are trapped by serum albumin to enhance amyloid-beta activation of endothelial cells. J Biol Eng. 2009;3:5.

28. Milojevic J, Melacini G. Stoichiometry and affinity of the human serum albumin-Alzheimer's Abeta peptide interactions. Biophys J. 2011;100:183-92.

29. Schwarzman AL, Goldgaber D. Interaction of transthyretin with amyloid beta-protein: binding and inhibition of amyloid formation. Ciba Found Symp. 1996;199:146-60. discussion 160-4.

30. Saido T, Leissring MA. Proteolytic degradation of amyloid beta-protein. Cold Spring Harb Perspect Med. 2012;2:a006379.

31. Kumar S, Singh S, Hinze D, Josten M, Sahl HG, Siepmann M, Walter J. Phosphorylation of amyloid-beta peptide at serine 8 attenuates its clearance via insulin-degrading and angiotensin-converting enzymes. J Biol Chem. 2012;287:8641-51.

32. Hulmes JD, Bethea D, Ho K, Huang S-P, Ricci DL, Opiteck GJ, Hefta SA. An investigation of plasma collection, stabilization, and storage procedures for proteomic analysis of clinical samples. Clin Proteomics. 2004;1:17-31.

33. Ossenkoppele R, Jansen WJ, Rabinovici GD, Knol DL, van der Flier WM, van Berckel BN, Scheltens P, Visser PJ, Amyloid PETSG, Verfaillie SC, et al. Prevalence of amyloid PET positivity in dementia syndromes: a metaanalysis. JAMA. 2015;313:1939-49.

34. Morris JC. The Clinical Dementia Rating (CDR): current version and scoring rules. Neurology. 1993;43:2412-4.

35. Lee DY, Lee KU, Lee JH, Kim KW, Jhoo JH, Kim SY, Yoon JC, Woo SI, Ha J, Woo Jl. A normative study of the CERAD neuropsychological assessment battery in the Korean elderly. J Int Neuropsychol Soc. 2004;10:72-81.

36. Association AP. Diagnostic and Statistical Manual of Mental Disorders. 4th ed. American Psychiatric Association Washington, DC. 1994;1-866.

37. McKhann GM, Knopman DS, Chertkow H, Hyman BT, Jack Jr CR, Kawas CH, Klunk WE, Koroshetz WJ, Manly JJ, Mayeux R, et al. The diagnosis of dementia due to Alzheimer's disease: recommendations from the National 
Institute on Aging-Alzheimer's Association workgroups on diagnostic guidelines for Alzheimer's disease. Alzheimers Dement. 2011;7:263-9.

38. Lee JH, Lee KU, Lee DY, Kim KW, Jhoo JH, Kim JH, Lee KH, Kim SY, Han SH, Woo Jl. Development of the Korean version of the Consortium to Establish a Registry for Alzheimer's Disease Assessment Packet (CERAD-K): clinical and neuropsychological assessment batteries. J Gerontol B Psychol Sci Soc Sci. 2002;57:P47-53.

39. Piccinin AM, Muniz-Terrera G, Clouston S, Reynolds CA, Thorvaldsson V, Deary IJ, Deeg DJ, Johansson B, Mackinnon A, Spiro 3rd A, et al. Coordinated analysis of age, sex, and education effects on change in MMSE scores. J Gerontol B Psychol Sci Soc Sci. 2013;68:374-90.

40. Weiss SJ. Tissue destruction by neutrophils. N Engl J Med. 1989;320:365-76.

41. Park JC, Baik SH, Han SH, Cho HJ, Choi H, Kim HJ, Choi H, Lee W, Kim DK, Mook-Jung I. Annexin A1 restores Abeta1-42-induced blood-brain barrier disruption through the inhibition of RhoA-ROCK signaling pathway. Aging Cell. 2017;16:149-61.

42. Fanali G, di Masi A, Trezza V, Marino M, Fasano M, Ascenzi P. Human serum albumin: from bench to bedside. Mol Aspects Med. 2012;33:209-90.

43. Jupin M, Michiels PJ, Girard FC, Spraul M, Wijmenga SS. NMR metabolomics profiling of blood plasma mimics shows that medium- and long-chain fatty acids differently release metabolites from human serum albumin. J Magn Reson. 2014:239:34-43.

44. Rangachari V, Moore BD, Reed DK, Sonoda LK, Bridges AW, Conboy E, Hartigan D, Rosenberry TL. Amyloid-beta(1-42) rapidly forms protofibrils and oligomers by distinct pathways in low concentrations of sodium dodecylsulfate. Biochemistry. 2007:46:12451-62.

45. Youden WJ. Index for rating diagnostic tests. Cancer. 1950;3:32-5.

46. Bibl M, Welge V, Esselmann H, Wiltfang J. Stability of amyloid-beta peptides in plasma and serum. Electrophoresis. 2012;33:445-50.

47. Faurschou M, Borregaard N. Neutrophil granules and secretory vesicles in inflammation. Microbes Infect. 2003;5:1317-27.

48. Chertov O, Yang D, Howard OM, Oppenheim JJ. Leukocyte granule proteins mobilize innate host defenses and adaptive immune responses. Immunol Rev. 2000;177:68-78.

49. Desrochers PE, Weiss SJ. Proteolytic inactivation of alpha-1-proteinase inhibitor by a neutrophil metalloproteinase. J Clin Invest. 1988;81:1646-50.

50. Boyanton Jr BL, Blick KE. Stability studies of twenty-four analytes in human plasma and serum. Clin Chem. 2002;48:2242-7.

51. Baker AH, Edwards DR, Murphy G. Metalloproteinase inhibitors: biological actions and therapeutic opportunities. J Cell Sci. 2002;115:3719-27.

52. Clark S, Youngman LD, Palmer A, Parish S, Peto R, Collins R. Stability of plasma analytes after delayed separation of whole blood: implications for epidemiological studies. Int J Epidemiol. 2003;32:125-30.

53. Zimmerman L, Li M, Yarbrough WG, Slebos RJ, Liebler DC. Global stability of plasma proteomes for mass spectrometry-based analyses. Mol Cell Proteomics. 2012:11:M111-M014340.

54. Vina J, Lloret A. Why women have more Alzheimer's disease than men: gender and mitochondrial toxicity of amyloid-beta peptide. J Alzheimers Dis. 2010;20 Suppl 2:S527-33.

55. Chartier-Harlin MC, Parfitt M, Legrain S, Perez-Tur J, Brousseau T, Evans A Berr C, Vidal O, Roques P, Gourlet V, et al. Apolipoprotein E, epsilon 4 allele as a major risk factor for sporadic early and late-onset forms of Alzheimer's disease: analysis of the 19q13.2 chromosomal region. Hum Mol Genet. 1994;3:569-74

56. Assini A, Cammarata S, Vitali A, Colucci M, Giliberto L, Borghi R, Inglese ML, Volpe S, Ratto S, Dagna-Bricarelli F, et al. Plasma levels of amyloid betaprotein 42 are increased in women with mild cognitive impairment. Neurology. 2004;63:828-31.

57. Lopez OL, Kuller LH, Mehta PD, Becker JT, Gach HM, Sweet RA, Chang YF, Tracy R, Dekosky ST. Plasma amyloid levels and the risk of AD in normal subjects in the Cardiovascular Health Study. Neurology. 2008;70:1664-71.

\section{Submit your next manuscript to BioMed Central and we will help you at every step:}

- We accept pre-submission inquiries

- Our selector tool helps you to find the most relevant journal

- We provide round the clock customer support

- Convenient online submission

- Thorough peer review

- Inclusion in PubMed and all major indexing services

- Maximum visibility for your research

Submit your manuscript at www.biomedcentral.com/submit
Biomed Central 